\title{
A numerical solution to an inverse unsteady-state heat transfer problem involving the Trefftz functions
}

\author{
Beata Maciejewska ${ }^{1, *}$, Magdalena Piasecka $^{2}$ \\ ${ }^{1}$ Faculty of Management and Computer Modelling \\ ${ }^{2}$ Faculty of Mechatronics and Mechanical Engineering \\ Kielce University of Technology, Al. 1000-lecia P.P. 7, 25-314 Kielce, Poland
}

\begin{abstract}
This paper shows the results concerning flow boiling heat transfer in an asymmetrically heated vertical minichannel. The heated element for FC-72 Fluorinert flowing in that minichannel was a thin foil. The foil surface temperature was monitored continuously at 18 points by K-type thermocouples from the outer foil surface. Fluid temperature and pressure in the minichannel inlet and outlet, current supplied to the foil and voltage drop were also monitored. Measurements were carried out at $1 \mathrm{~s}$ intervals. The objective was to determine the heat transfer coefficient on the heated foil-fluid contact surface in the minichannel. It was obtained from the Robin boundary condition. The foil temperature was the result of solving the nonstationary two-dimensional inverse boundary problem in the heated foil. Using the FEM combined with Trefftz functions as basis functions solved the problem. The unknown temperature values at nodes were calculated by minimising the adequate functional. The values of local heat transfer coefficients were consistent with the results obtained by the authors in their previous studies when steady-state conditions were analysed. This time, however, these values were analysed as time dependent, which facilitated observation of coefficient changes that were impossible to observe under the steady-state conditions.
\end{abstract}

\section{Introduction}

Confronted with the recent broadening of the application range for narrow flow boiling heat transfer systems, researchers are devoting extensive experimental and theoretical studies to better understand heat transfer processes in mini gaps. The review of relevant literature is provided in [1-4]. In their previous works, the authors focused on steady-state flow boiling heat transfer. Their current research projects are designed to evaluate flow boiling heat transfer in minichannels under unsteady state conditions. A growing body of research is using advanced numerical analysis in simulations of heat and mass transport processes in channels. Experiments concerning time-dependent flow parameters are shown and discussed in, among others, [5-9].

Heat transfer coefficient identification belongs to the family of inverse heat conduction problems [10-12] solved with the use of many numerical methods, including the Trefftz method [13]. The method involves approximating unknown solution to a differential equation by means of a linear combination of functions strictly satisfying the governing differential equation. Details related to the Trefftz method are provided in [1424]. This method is suitable for solving direct [13-15, $22]$, inverse [17-24], stationary [17, 21, 24] and nonstationary $[18,19,20,22]$ problems. This paper generalizes the results showed in [18].
Based on Trefftz functions, the authors 2D time-andspace basis functions in FEM was constructed. The experimental time-dependent measurements were used to develop a method for determining the heat transfer coefficient.

\section{Experimental research}

The essential part of the experimental stand is the measurement module with two parallel minichannels. The schematic diagram of the measurement module, is shown in figure 1. Each minichannel was $1.7 \mathrm{~mm}$ deep, $16 \mathrm{~mm}$ wide, and $180 \mathrm{~mm}$ long. The heated element for FC-72 Fluorinert flowing in the minichannels was a thin foil $(0.1 \mathrm{~mm}$ thick) made of Haynes-230 alloy. In the tested minichannel, the temperature of the outer surface of the foil was measured by means of thermoelements. The other side of the minichannel was observed through a glass pane to identify the two-phase flow patterns. Two thermocouples and two pressure converters were installed at the inlet and outlet of the minichannels. The infrared temperature measurements realized in the other minichannel was not the case in this work but it was used for rough comparison. The experimental stand was discussed in [1-4].

* Corresponding author:beatam@tu.kielce.pl 


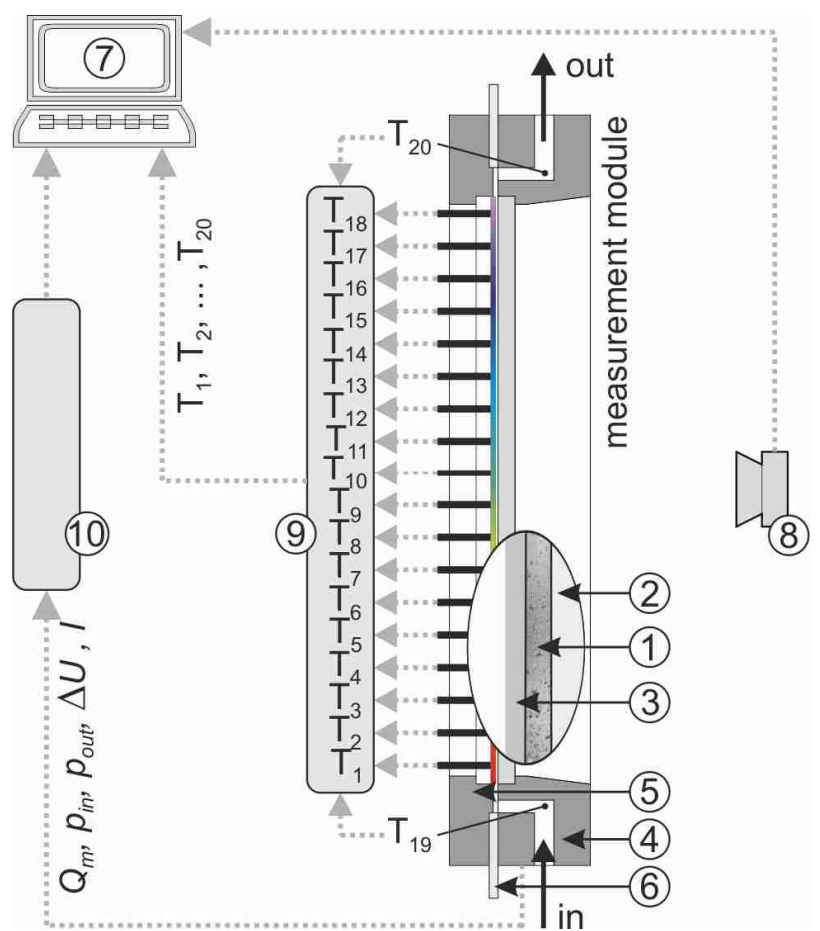

Fig. 1. The schematic diagram of the measurement module: 1-minichannel, 2-glass pane, 3-heated foil, 4-channel body, 5-front cover, 6- copper electrode, 7-DaqLab 2005 data acquisition station, 8-high speed camera, 9 -pc computer, 10- MCC data acquisition device, experimental parameters: $Q_{m}$ - mass flow rate, $p_{\text {in/out }}$ - pressure at the inlet/outlet to the minichannel, $\Delta U$ - voltage drop, $I$ - current.

In the experimental series, the current supplied to the heated foil was gradually increased within $240 \mathrm{~s}$. The temperature of the foil surface were recorded continuously at 18 points by K-type thermocouples placed at the outer surface along the central, axially symmetric axis of the channel. The signals from these thermocouples and thermocouples controlling fluid temperature at the inlet and outlet to the minichannel were recorded using a DaqLab 2005 data acquisition station. The thermocouples recording foil temperature at the selected points were marked in figure 1 as $\mathrm{T}_{1} . . \mathrm{T}_{18}$, two thermocouples installed at the inlet and outlet of the minichannel - as $\mathrm{T}_{19}$ and $\mathrm{T}_{20}$. The current supplied to the foil, the voltage drop across the foil, the pressure of the fluid at the minichannel inlet and outlet and mass flow rate were recorded using an MCC data acquisition device with analogue signal conditioning. All measurements were performed at 1-second intervals.

\section{Analysis and modelling}

Two-dimensional nonstationary heat flow in the minichannel was assumed, neglecting temperature variation along the width of the minichannel. The dimensions taken into account included dimension $x$ along the flow direction and dimension $y$, perpendicular to the direction of flow, related to the heated foil thickness. Only the subcooled boiling region was analysed. Local heat transfer coefficients were calculated from the third type boundary condition:

$$
\alpha(x, t)=\frac{-\lambda \frac{\partial T}{\partial y}(x, \delta, t)}{T(x, \delta, t)-T_{f}(x, t)}
$$

where: $\delta$ is the thickness of the heated foil, $\lambda$ is the thermal conductivity of the heated foil, $T$ is the foil temperature, $T_{f}$ is the fluid temperature calculated from the assumption of the linear distribution of the fluid temperature along the minichannel.

To find the foil temperature, $T$, the inverse heat conduction problem in the heated foil was solved. Foil temperature variation over time is described by the nonhomogeneous heat equation

$$
\frac{\partial^{2} T}{\partial x^{2}}+\frac{\partial^{2} T}{\partial y^{2}}-\frac{\rho c_{p}}{\lambda} \frac{\partial T}{\partial t}=-\frac{q_{V}(t)}{\lambda},(x, y) \in \Omega, t>0
$$

and the initial and the boundary conditions:

$$
\begin{gathered}
T(x, y, 0)=T_{0}(x, y) \\
\frac{\partial T}{\partial x}(0, y, t)=0 \\
\frac{\partial T}{\partial x}(L, y, t)=0 \\
\lambda \frac{\partial T}{\partial y}(x, 0, t)=q_{\text {loss }}(t)
\end{gathered}
$$$$
T\left(x_{p}, 0, t_{m}\right)=T_{p}\left(t_{m}\right) \text { for } p=1,2, \ldots P ; m=1,2, \ldots M
$$

where: $\Omega=\left\{(x, y) \in R^{2}: 0<x<L, \quad 0<y<\delta\right\}, L$ - heated foil length, $\rho$ - heated foil density, $c_{p}$ - heated foil specific heat, $q_{\text {loss }}-$ heat losses to the surroundings, estimated as in [2], $T_{p}$ - thermocouple-measured foil temperature, $\mathrm{P}$ - number of measurements, $M$ - number of time intervals, $\lambda, \delta$-defined as for Eq. (1).

The volumetric heat flux $q_{V}$ was calculated from

$$
q_{V}(t)=\frac{I(t) \Delta U(t)}{A \delta}
$$

where $I$ - current supplied to the heated foil, $\Delta U$ - drop in voltage along the length of the heated foil, $A$ - surface area of the heated foil in contact with the fluid, $\delta$-defined as for Eq. (1).

The inverse problem, Eqs. (2-7), was solved using the FEMT (the FEM with Trefftz functions as basis functions) in time-space elements. In order to find an approximate solution of this problem, the time interval $<0, t\rangle$ was divided into $M$ subintervals $<(m-1) \Delta t, m \Delta t>$, for $m=1,2, \ldots, M$, where $\Delta t$ denote the length of the time interval. The time-space region $\bar{\Omega}=\Omega \times<(m-1) \Delta t, m \Delta t>$, for a fixed $m$, was 
divided into $L 1 \cdot L 2$ cuboidal elements with 8 nodes in each of them, where $L 1$ was the number of elements in the $x$-axis direction and $L 2$ was the number of elements in the $y$-axis direction. In each element $\Omega_{j}$, $j=1,2, \ldots, L 1 \cdot L 2$, the set of basis functions were characterized in nodes $\left(x_{i}, y_{i}, t_{i}\right)$ by the following property

$$
f_{j k}\left(x_{i}, y_{i}, t_{i}\right)=\delta_{k i}, \quad i=1,2, \ldots, N
$$

where: $\delta_{k i}$ denotes the Kronecker delta, $j$ is the element number, $k$ is the basis function number in $j$-th element, $N$ is the number of nodes in the element.

The temperature of the heated foil in each element $\Omega_{j}$ for a fixed $m$ was approximated with a formula containing a linear combination of the basis functions $f_{j k}(x, y, t)$ :

$$
T_{m}^{j}(x, y, t)=\tilde{u}(x, y, t)+\sum_{k=1}^{N}\left(\widehat{T}^{n}-\tilde{u}\left(x_{n}, y_{n}, t_{n}\right)\right) f_{j k}(x, y, t)
$$

where $n$ denotes the node number in the entire domain $\bar{\Omega}, \tilde{u}\left(x_{n}, y_{n}, t_{n}\right)$ is the particular solution in the $n$-th node of domain $\bar{\Omega}, \widehat{T}^{n}$ is the unknown temperature in the $n$-th node of domain $\bar{\Omega}$.

From the basis function properties it follows that coefficients $\hat{T}^{n}$ are the values of temperature in the nodes of $\bar{\Omega}$.

All unknown coefficients $\widehat{T}^{n}$ of linear combination in Eq. (10) were calculated by minimizing the functional that describes the mean square error of the approximate temperature and its derivatives on the boundary in the initial time and along common edges of the adjacent elements.

\section{Results and discussion}

The study was devoted to the heat transfer coefficient identification in the regions of subcooled and saturated boiling. The coefficient was found by solving the inverse heat conduction problem with used the FEM based on Trefftz-type basis functions in time-space subdomains. The calculations were performed using the timedependent temperature measurements.

The relationship between the temperature of the heat transfer coefficient and the distance from the minichannel inlet, were determined for three times: $t_{1}=10 \mathrm{~s}, t_{50}=50 \mathrm{~s}$ and $t_{80}=80 \mathrm{~s}$ is shown in figure 2. These data were selected to present the results obtained for the subcooled boiling region. The values of the heat transfer coefficient in the saturated boiling region, calculated for three other times, i.e., $t_{125}=125 \mathrm{~s}$, $t_{185}=185 \mathrm{~s}$ and $t_{245}=245 \mathrm{~s}$, as a function of the distance from the minichannel inlet, are presented in figure 3 .

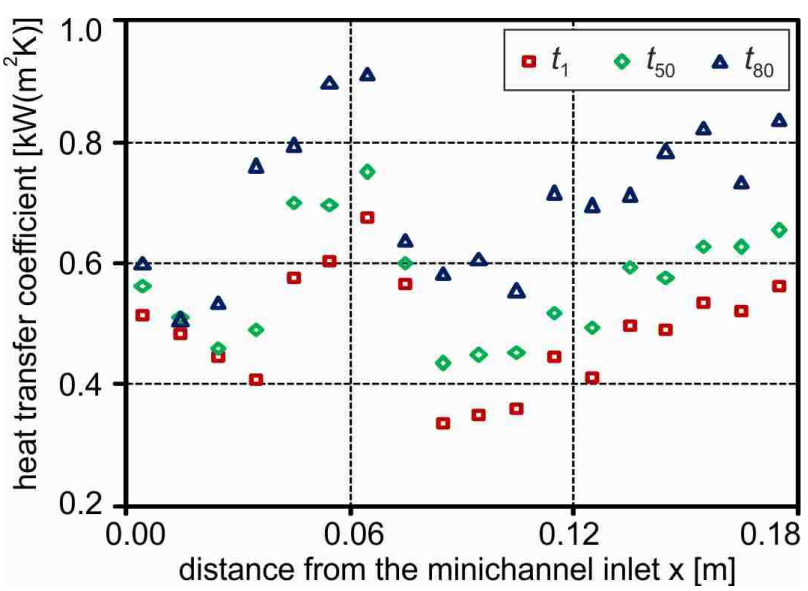

Fig. 2. Heat transfer coefficient vs. the distance from the minichannel inlet for $t_{1}=10 \mathrm{~s}, t_{50}=50 \mathrm{~s}, t_{80}=80 \mathrm{~s}$, the subcooled boiling region, experimental parameters: $q_{V}=1.1 \cdot 10^{5} \mathrm{~kW} / \mathrm{m}^{3}, p_{i n}=113.8 \mathrm{kPa}$ for $t_{10}=10 \mathrm{~s}$, $q_{V}=1.4 \cdot 10^{5} \mathrm{~kW} / \mathrm{m}^{3}, p_{\text {in }}=114.4 \mathrm{kPa}$ for $t_{50}=50 \mathrm{~s}$, $q_{V}=1.8 \cdot 10^{5} \mathrm{~kW} / \mathrm{m}^{3}, p_{i n}=115.4 \mathrm{kPa}$ for $t_{80}=80 \mathrm{~s}$; average $Q_{m}=0.012 \mathrm{~kg} / \mathrm{s}$.

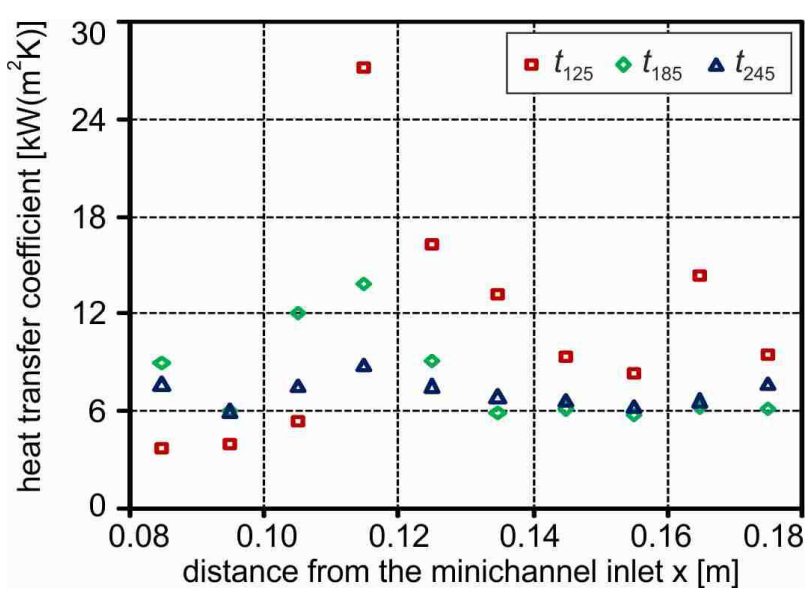

Fig. 3. Heat transfer coefficient vs. the distance from the minichannel inlet for $t_{125}=125 \mathrm{~s}, t_{185}=185 \mathrm{~s}$ and $t_{245}=245 \mathrm{~s}$, the saturated boiling region, experimental parameters: $q_{V}=2.79 \cdot 10^{5} \mathrm{~kW} / \mathrm{m}^{3}, p_{\text {in }}=118.5 \mathrm{kPa}$ for $t_{125}=125 \mathrm{~s}$, $q_{V}=3.93 \cdot 10^{5} \mathrm{~kW} / \mathrm{m}^{3}, p_{\text {in }}=125.1 \mathrm{kPa}$ for $t_{185}=185 \mathrm{~s}$, $q_{V}=3.85 \cdot 10^{5} \mathrm{~kW} / \mathrm{m}^{3}, p_{\text {in }}=12.99 \mathrm{kPa}$ for $t_{245}=245 \mathrm{~s}$; average $Q_{m}=0.012 \mathrm{~kg} / \mathrm{s}$.

These results confirm those obtained by the authors in their earlier studies when steady state conditions were analysed [1-4]. Under the subcooled boiling, local heat transfer coefficients had relatively low values up to $1000 \mathrm{~W} /\left(\mathrm{m}^{2} \mathrm{~K}\right)$, figure 2 . A scatter of the heat transfer coefficient values in the range 300 to $900 \mathrm{~W} /\left(\mathrm{m}^{2} \mathrm{~K}\right)$ can be observed in this boiling region, in particular in the beginning minichannel length up the distance of $0.8 \mathrm{~m}$ from the minichannel inlet. Further in the channel, the heat transfer coefficient developed uniformly showing increasing values for the three times under analysis, $t_{1}$, $t_{50}$ and $t_{80}$. Under the saturated boiling, local heat transfer coefficients achieved high values, figure 3 . The heat transfer coefficient was the highest at the beginning of the nucleate saturated boiling up to $30 \mathrm{~kW} /\left(\mathrm{m}^{2} \mathrm{~K}\right)$. Results obtained for $t_{125}$ and $t_{185}$ indicate sinusoid fluctuation as a function of the distance from the minichannel inlet. At the final stage of the experiment, 
the results obtained for $t_{245}$ confirmed that in the fully developed boiling region for higher vapour phase fractions, the heat transfer coefficient decreased to $5-7 \mathrm{~kW} /\left(\mathrm{m}^{2} \mathrm{~K}\right)$ at the minichannel outlet. This means that the coefficients in the subcooled boiling region were several times as big as those in the fully developed boiling region.

Figures 4 and 5 show the heat transfer coefficient vs. distance with the increasing heat flux being supplied to the foil, separately for the subcooled and saturated boiling regions, respectively.
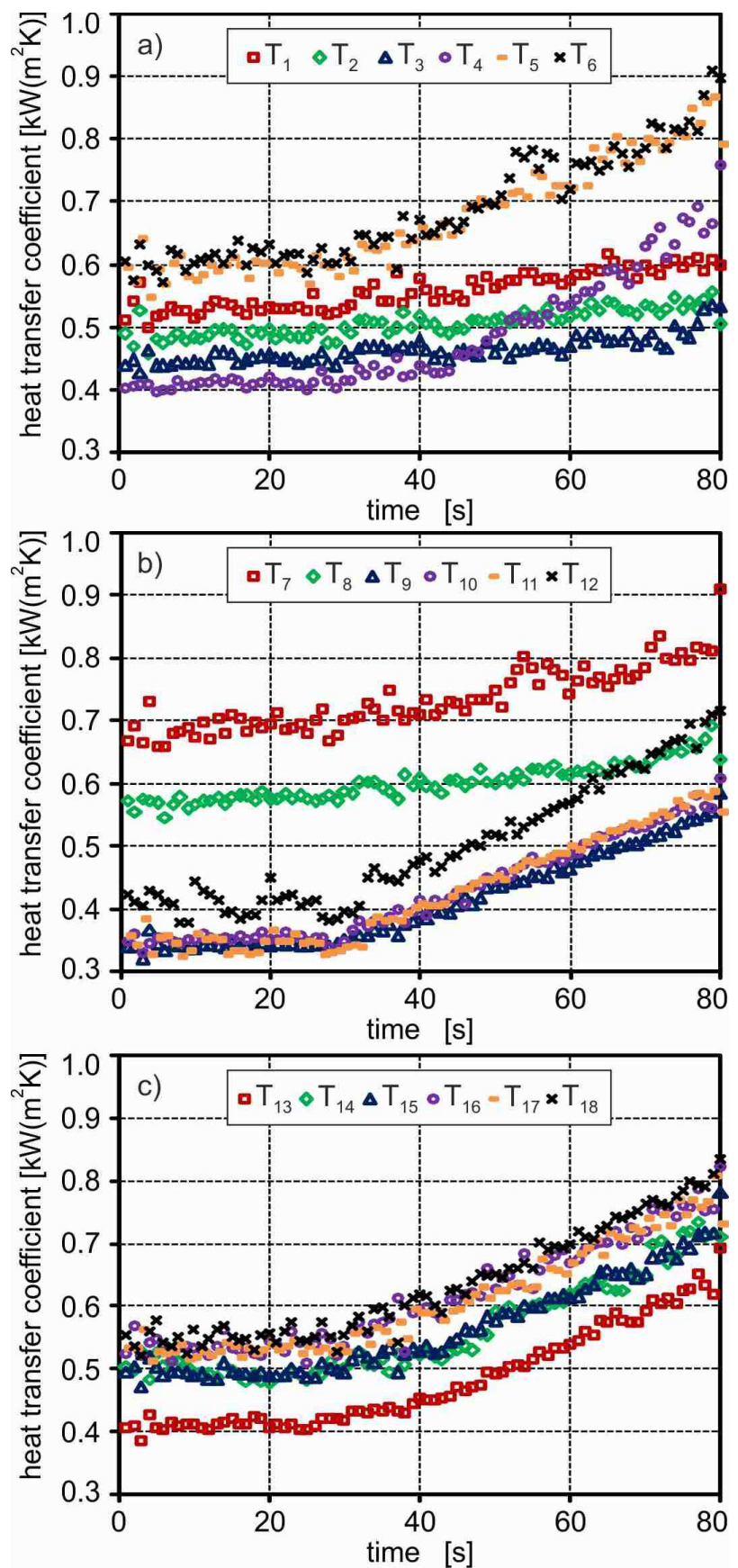

Fig. 4. Heat transfer coefficient vs. time, results for the subcooled boiling region calculated on the basis of temperature measurements from 18 thermocouples: a) thermocouples $T_{1}$ to $\mathrm{T}_{6} ;$ b) thermocouples $\mathrm{T}_{7}$ to $\mathrm{T}_{12} ;$ a) thermocouples $\mathrm{T}_{13}$ to $\mathrm{T}_{18}$; experimental parameters: $q_{V}$ from $1.12 \cdot 10^{5} \mathrm{~kW} / \mathrm{m}^{3}$ to $1.8 \cdot 10^{5} \mathrm{~kW} / \mathrm{m}^{3}, p_{\text {in }}$ from $113.7 \mathrm{kPa}$ to $115.4 \mathrm{kPa}$, average $Q_{m}=0.012 \mathrm{~kg} / \mathrm{s}$.
In detail, the results obtained for:

- the subcooled boiling region are shown in figure 4 as local values of the heat transfer coefficient calculated on the basis of the foil temperature measured at all selected points along the minichannel (18 points),

- the saturated boiling region are shown in figure 5 as local heat transfer coefficients calculated on the basis of the foil temperature measured at 10 points near the minichannel outlet (thermocouples from $T_{9}$ to $T_{18}$, see figure 1).
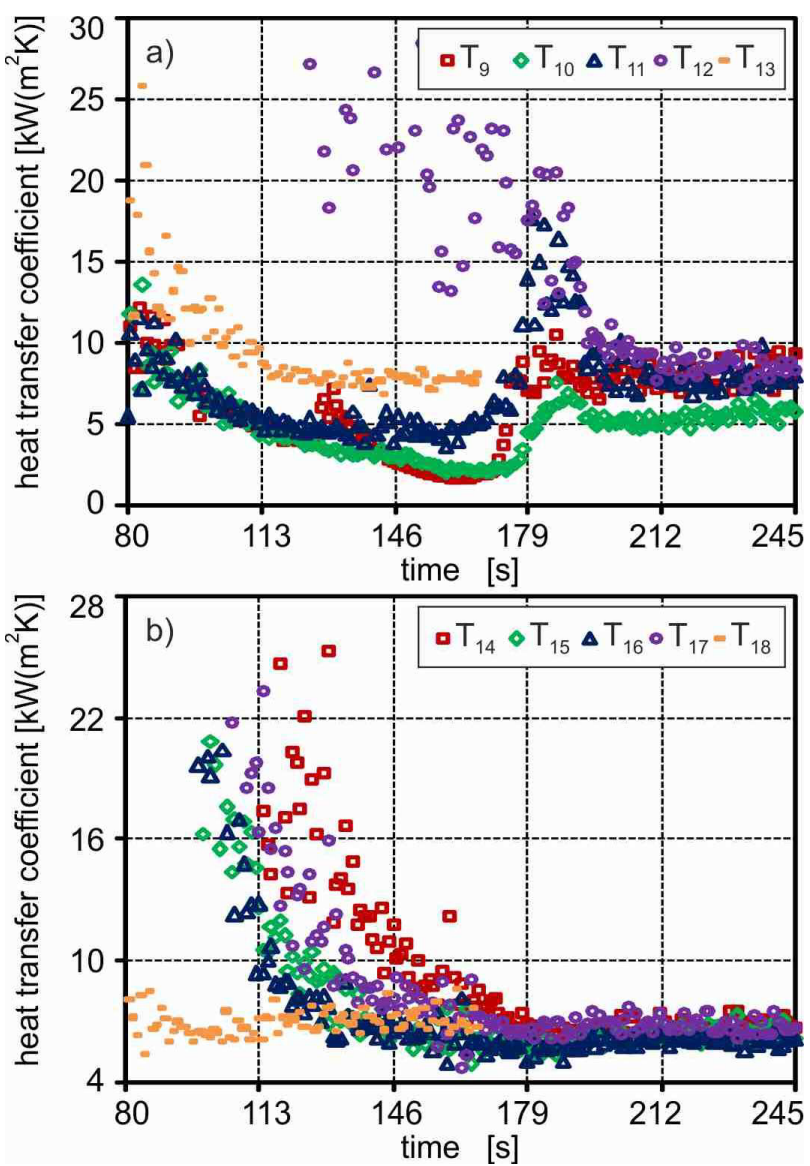

Fig. 5. Heat transfer coefficient vs. time, results for the saturated boiling region calculated on the basis of temperature measurements from thermocouples $\mathrm{T}_{9}$ to $\mathrm{T}_{18}$, experimental parameters: $q_{V}$ from $1.8 \cdot 10^{5} \mathrm{~kW} / \mathrm{m}^{3}$ to $3.86 \cdot 10^{5} \mathrm{~kW} / \mathrm{m}^{3}$, $p_{\text {in }}$ from $115.4 \mathrm{kPa}$ to $128.9 \mathrm{kPa}$, average $Q_{m}=0.012 \mathrm{~kg} / \mathrm{s}$.

During the analysis of time-dependent values of the coefficient, figures 4 and 5 , the surface temperature recorded by thermocouples $T_{9}, T_{10}$ and $T_{11}$ indicates coefficient value increase following its drop. Probably the fully developed boiling region was not reached within 150-170 seconds at the channel mid-length. Thermocouple $\mathrm{T}_{12}$ suggests an incremental increase in the coefficient value at that time and channel length. The results from thermocouples $\mathrm{T}_{13}$ to $\mathrm{T}_{18}$ indicate a substantial reduction in the value of the coefficient, which at the end stage of the experiment levelled off at a low level just at the channel outlet. 


\section{Conclusions}

The authors of this paper investigated flow boiling heat transfer in a vertical minichannel in subcooled and saturated boiling regions. A thin foil was the heated element for FC-72 Fluorinert flowing in the minichannel. Mounted at the outer surface of the foil, K-type thermocouples observed the surface temperature at 18 points. Data acquisition stations monitored the experimental parameters. The measurements were performed at $1 \mathrm{~s}$ intervals.

The numerical calculations aimed at determining the value of heat transfer coefficient at the foil-fluid interface in the minichannel. A two-dimensional unsteady-state inverse boundary problem was solved in time-dependent subdomains to determine the foil temperature. The method used to solve the inverse problem was FEMT. Unlike the classical FEM, in which shape functions depend only on space variables, the FEMT method applied in the paper used twodimensional space-time basis functions. Whereas the FEM requires formulating boundary conditions on all boundaries, the proposed method, FEMT, can be used to solve both direct and inverse problems. Although the approximate foil temperature satisfies differential equation strictly, it meets the boundary conditions only approximately. The calculation results show that to identify the time-dependent heat transfer coefficient, the approximate solution can be constructed with the use of time-dependent Trefftz functions.

The values of local heat transfer coefficient confirm the results obtained by the authors in their earlier studies when steady-state conditions were analyzed. Under the subcooled boiling, local heat transfer coefficients had relatively low values. Under the saturated boiling local heat transfer coefficients reached high values. At the final phase of the experiment, the result obtained confirmed that heat transfer coefficient values decreased in the fully developed boiling region for higher fractions of the vapour phase. The results, in the form of the timedependent local heat transfer coefficient values, showed the local coefficient heat flux increase-related changes that were impossible to observe under steady-state conditions. The authors are planning to verify the results in their further works.

\section{ACKNOWLEDGMENTS}

The research was supported in part by the Polish National Science Centre (No. DEC-2013/09/B/ST8/02825).

\section{References}

1. M. Piasecka, Int. J. Refrig. 56, 198-212 (2015)

2. M. Piasecka, K. Strąk, B. Maciejewska, Heat Transf. Eng. 38 (3), 332-346 (2017)

3. M. Piasecka, B. Maciejewska, Exp. Therm. Fluid Sci. 68, 459-467 (2015)

4. M. Piasecka, Int. J. Heat Mass Transf. 81, 114-121 (2015)
5. A. Majumder, B. Mehta, S. Khandekar, Int. J. Therm. Sci, 66, 8-18 (2013)

6. B. Mehta, S. Khandekar, Int. J. Therm. Sci, 91, 157-166 (2015)

7. Z. Zhou, X. Xu, X. Liang, Exp. Therm. Fluid Sci., 34, 1409-1414 (2010)

8. J. Taler, B. Wójtowicz, Arch. Thermod., 28, 3-14 (2007)

9. P. Ocłoń, S. Łopata, M. Nowak, Heat Mass Transf., 51, 553-566 (2015)

10. A. Tikhonov, V. Arsenin, Solution of ill-posed problems (Wiley, New York, 1977)

11. J. V. Beck, B. Blackwell, C. R. St. Clair, Inverse heat conduction. Ill-posed Problems (Wiley Interscience Publ., New York, 1985)

12. M. N. Özisi̧k., H. R. B. Orlande, Inverse heat transfer: fundamentals and applications. Fundamentals and Applications (Taylor \& Francis, New York, 2000)

13. E. Trefftz, Proc. Int. Kongress für Technische Mechanik, Zürich, 131-137 (1926)

14. I. Herrera, Meth. Partial Diff. Eqs., 16, 561-580 (2000)

15. V. Kompis, F. Konkol, M. Vasko, Comp. Assis. Mech. Eng. Sci., 8, 385-395 (2001)

16. Z.-C. Li, T.-T. Lu, H.-T. Huang, H.-D Cheng Alexander, Num. Meth. Part. Diff. Eqs., 23, 1-52 (2006)

17. K. Grysa, A. Maciąg, A. Pawińska, Int. J. Heat Mass Transf., 55, 7336-7340 (2012)

18. M. J. Ciałkowski, J. Therm. Sci., 11, 163-171 (2002)

19. M. J. Ciałkowski, K. Grysa, J. Inv. Ill-Posed Prob., 18, 595-616 (2010)

20. K. Grysa, B. Maciejewska, J. Theor. Appl. Mech., 51, 251-264 (2013)

21. S. Hożejowska, R. Kaniowski, M.E. Poniewski, Exp. Therm. Fluid Sci., 78, 18-29 (2016)

22. A. Maciąg, Int. J. Num. Meth. Biomed. Eng., 27, 1107-1125 (2011)

23. S. Blasiak, A. Pawinska, Int. J. Heat Mass Transfer, 90, 710-718 (2015)

24. B. Maciejewska, M. Piasecka, Heat Mass Transfer, DOI: 10.1007/s00231-016-1895-1 (2016) 